1. TRANCHANT, L. La cinématographie pour tous. Paris: Comptoir d'éditions de "Cinemarevue", 1913. (Ver a Introduçâ.) Ao que parece, foi [Riccioto] Canudo quem lançou a expressão "a sétima arte" em relação à cinematografia.

2. DUPUIS, Ch. La cinématographie. Cahors: A. Coueslant, 1913. p. 3.

3. Cinéma-Revue, agosto de 1911, $n^{\circ} 5$, p. 6.

4. Apud: $\angle A$ QUESTION cinématographique: son éta actuel, sa solution. Lille: L. Danel, 1912. p. 30 [autoria desconhecida].

\title{
O NASCIMENTO DO CINEMA E A SIMULTANEIDADE*
}

\section{Pär Bergman \\ Tradução: Júlio Bernardo Machinski**}

Muitas pessoas acreditavam que o cinema do pré-guerra era um meio de recreação qualquer que podia ser comparado às gomas de mascar e ao circo; mas, para muitos outros, o cinema era de extrema importância - até mesmo "a oitava maravilha do mundo". ${ }^{1}$ Em 1913, época em que há, em Paris, cerca de 200 cinemas e, em Marselha e Lyon, uma quarentena em cada uma das cidades, Charles Dupuis escreve o seguinte no início de um pequeno livro dedicado ao cinema: "Uma fada boa previu que, sem dúvida, o cinema teria, desde o seu nascimento, um brilhante destino, pois, mal chegado ao mundo, ele conquistou todos os favores e, hoje, menos de vinte anos depois de seu início, sua reputação é universal”. ${ }^{2}$
** jmachinski@yahoo.com.br

em Literatura pela Universidade Federal de Santa Catarina e doutorando no Programa de Pós-Graduação em Teoria e História Literária do Instituto de Estudos da Linguagem da Unicamp.

A forte influência exercida pelo cinema sobre os espectadores desperta discussões acaloradas, e os produtores de cinema estão dispostos a dar ao público "a ilusão completa de assistir (...) a uma cena que se desenrola realmente sob seus olhos". ${ }^{3} \mathrm{O}$ cinema impõe-se a todo mundo e ao mundo inteiro: Carlitos é admirado simultaneamente em Tóquio, em Roma, em Chicago e em Buenos Aires. O cinema é, como escreveu um dos pioneiros do cinema francês no Cine-Journal, em 1912: "uma sexta [sic] arte que, no mesmo segundo, faz vir lágrimas aos olhos do árabe e do esquimó (...)”.

Desde a sua infância, o cinema visou mostrar o mundo inteiro aos espectadores. A conclusão de uma pesquisa era
Tradução da parte final da introdução ("Le 'Mythe du Moderne' au début du XX siècle") do livro "Modernolatria" et "Simultaneità": recherches sur deux tendences dans l'avant-garde littéraire en Italie et en France à la veille de la première guerre mondial, publicado em 1962, por Pär Bergman, originalmente apresentado como tese de doutorado na Universidade de Uppsala. No fragmento selecionado, após abordar o impacto que algumas invenções tecnológicas no início do século XX (como bicicleta, o automóvel, o avião, os transatlânticos e o telégrafo) causaram sobre os modos de viver e sobre a produção artística da época, Bergman concentra sua atenção em aspectos que cercam o surgimento do cinema abordando as característica da linguagem cinematográfica e os efeitos dessa então novíca arte sobre a percepcão do arpaço do tempo.

Agradecemos ao autor pela gentileza de autor pela glicacão bem como à professora Maria Eugenia Boaventura, por ter possibilitado o acesso ao texto possibilitad 
9. Bergman deve estar referindose a Kid Auto Races at Venice, tambem conhecido, em inglês, como The Pest; Charlot est

a de que podia ser observado que o cinema se servia, entre $\quad$ (1912), ${ }^{9}$ e Georges Méliès, célebre, sobretudo, por suas realiun film. \pm 2000 : arte teatro
und único, Bari, 1931. p. 28 ss. Cf. CARLSOON dagars kinematografi varra dagars kinematografi [sobre a filmtidning Estocolmo, mark $1909, n^{\circ} 3$, p. 1 .

6. DOUMIC, R. Revue dramatique: l'âge du cinéma. Revue des deux mondes, 15 de agosto de 1913, p 919.

7. Cinéma-Revue, agosto de 1911 $n^{\circ} 5$, Introdução.

8. Ver, por exemplo, SADOUL, G. Histoire générale du cinéma, p. 264. outras, das seguintes expressões:

a África, as moçoilas, os cossacos, o Pólo Norte, a Oceania, os negros, os negreiros, a Europa, o arrombamento, os condenados, a América, os contrabandistas de álcool, a grande quebra da bolsa, os bon vivants às duas da manhã, a Torre Eiffel, a Ásia o Estreito de Dardanelos, o Oeste, o Leste, ursos polares, a selva, as pirâmides, o Coliseu $(. . .)^{5}$

Os primeiros filmes consistem em atualidades de toda espécie: "Em todas as regiões e sob todas as latitudes sucedem-se cerimônias, incidentes, acidentes, dramas e faits divers: imediatamente, eles são reproduzidos sobre a tela mágica." ${ }^{\circ} \mathrm{O}$ número de agosto de 1911 da Cinéma-Revue agrupa os novos filmes do mês sob três rubricas: filmes de viagem (que conduzem os espectadores, por exemplo, a Níjni Novgorod, ao Senegal, à Ístria, à Nápoles, ao Japão, à Hungria e à Melanésia), filmes cômicos e documentários, mostrando, entre outras coisas, a China, a Arábia, o Texas e a Austrália. ${ }^{7}$ Filmes já haviam sido realizados durante as expedições polares de $1906,{ }^{8}$ e o Cana do Panamá reaparecia a cada passo em documentários.

Note-se, também, o importante papel desempenhado pelos meios de transporte de todo tipo. Carlitos inicia-se no cinema em uma farsa cinematográfica intitulada La course d'auto

\begin{tabular}{|c|c|c|c|c|c|c|}
\hline EM TESE & BELO HORIZONTE & v. 21 & N. 2 & MAIO-AGO. 2015 & BERGMAN; MACHINSKI. 0 nascimento do cinema e a simultaneidade & P. 152-157 \\
\hline
\end{tabular}

zações cinematográficas dos livros de Júlio Verne, inventa em A viagem através do impossivel (Le voyage à travers l'impossible, 1904) o formidável "automabouloffe" ${ }^{2}$, síntese dos meios de transporte modernos. ${ }^{11}$ A viagem ao Pólo Norte em $A$ conquista do pólo (À la conquête du pôle, 1912), de Méliès, é feita, justamente, no "aerobus" do engenheiro Mabouloff. ${ }^{12}$ Desde a Exposição Universal de Paris, em 1900, os inventores franceses esforçaram-se em dar aos espectadores a ilusão completa de assistirem aos eventos que ocorriam sobre toda a superfície

content de lui, na França; Charlot si distingue, na Itália e Corrida de automóveis para meninos, no Brasil. Foi nesse filme de 1914 que, pela primeira vez, Charles Chaplin apareceu para o público completamente caracterizado como o "vagabundo". Quanto às diferenças e imprecisão dos títulos, Carlos Heitor Cony observa: "Há muita confusão sobre a titulagem desses primeiros filmes de Chaplin. $O$ próprio Senett [produtor], para alongar o tempo de projeção de alguns deles, fazia letreiros e subdivisões. Posteriormente, algumas das primeiras bobinas foram reunidas a outras numa espécie de filme único - o que torna extremamente difícil a pesquisa". Cf. CONY, C. H. Chaplin e outros ensaios. Rio de Janeiro: Topbooks, 2012. [N.T.].

10. Palavra-valise utilizada para designar, no filme, um veículo extraordinário que reúne as características do automóvel, do trem, do dirigível e do submarino. [N.T.] onde os espectadores viam, ao redor de si mesmos, cowboys a cavalo e podiam ouvir, por trás, aproximarem-se os PelesVermelha em perseguição etc. "Naquele dia, o público, jogado no centro da ação, quase deixou de ser espectador para identificar-se com os heróis". ${ }^{13}$

11. Ver BESSY, M.; LO DUCA, J.-M. Georges Méliès: mage. Paris: Prisma, 1945. p. 108

12. Ib., p. 61

13. SADOUL, G. Histoire générale du cinéma, II, p. 108. Sobre "as maravilhas da exposição de $1900 "$, ver o capítulo 6 , em geral. 
14. Film-Revue - hebdomadaire du cinématographe, janeiro de 1913 $n^{\circ} 2$, p. 10

15. DE GOURMONT, R. Cinématographe. Mercure de France, $1^{\circ}$ de setembro de 1907

vol. 69, p. 124.
Por certo, o poder do cinema de mostrar o mundo inteiro aos homens despertava entusiasmo e perplexidade. Em Film-Revue, cujas reproduções cinematográficas conduziam o leitor através do mundo inteiro, um entusiasta convidava todo mundo a olhar "Como o sol se põe" em Paris, nos Pirineus, nas margens do Nilo e no Mar Negro. ${ }^{14}$ Remy de Gourmont, num artigo escrito em 1907, destaca o poder do cinema de incutir nos espectadores um sentido daquilo que chegava simultaneamente de todos os cantos do mundo. O célebre crítico consegue representar aqui todos aqueles que, no início do século, graças ao cinema, puderam realizar seus sonhos de globetrotter e ir aonde bem lhes pareceu:

Amo a cinematografia. Ela satisfaz a minha curiosidade. Por ela eu faço a volta ao mundo e paro, segundo minha vontade, em Tóquio, em Singapura. Estou nas rotas mais malucas. Vou a Nova Iorque, que não é bonita, por Suez, que também não o é, e percorro na mesma hora as florestas do Canadá e as montanhas da Escócia; subo pelo Nilo até Cartum e, no instante seguinte, da ponte de um transatlântico, contemplo a extensão morna do Oceano. ${ }^{15}$

Parece evidente que o cinema contribuiu para criar um "sentido global" bastante amplo naquela época. É possível mesmo que os procedimentos técnicos do cinema, assim como os automóveis e os aviões, tenham contribuído para dar novas perspectivas, no sentido literal da palavra, a muitas pessoas. Obviamente que as câmeras cinematográficas do período, em contraste com a fotografia estática, destacaram-se em relação aos padrões de movimento. Já as séries de Muybridge, O cavalo em movimento ("The Horse in Motion"), e outras pesquisas semelhantes feitas durante a era pré-cinematográfica são significativas. "O movimento, é o seu (do cinema) triunfo e sua essência", ${ }^{16}$ movimento que pode ser condicionado por um objeto em movimento ou por uma câmera em movimento. Gance, um pioneiro do cinema francês, qualifica o cinema de "admirável síntese do movimento no espaço e no tempo". ${ }^{17}$

Uma vez que Georges Méliès, antes de se fazer produtor de cinema, era um prestidigitador renomado, os filmes baseados em truques e armações logo se tornaram muito na moda na França, e Méliès foi, talvez, o primeiro cineasta a utilizar em seus filmes a câmera lenta e a sobreposição. Parecem-nos de evidente importância as possibilidades do cinema de perturbar a ordem estabelecida do tempo. Já em 1896, os irmãos Lumière, projetando um filme de trás-pra-frente, mostraram aos espectadores uma parede rasa que se construía a si própria e, nesse mesmo ano, Méliès criava novas ilusões de tempo servindo-se da aceleração. Se o cineasta fotografa uma flor oito vezes por dia, a intervalos fixos, por quatro meses, e depois dispõe cinematograficamente essas fotografias, podemos ver desenvolver-se sobre a tela toda a vida da flor, em um minuto e meio. ${ }^{18}$
16. Revue des deux mondes, 15 de agosto de 1913, p. 924

17. Apud: La question cinématographique, p. 30

18. Ver, por exemplo, Revue lumineuse, 1907, p. 160. 
20. Cf. MARTIN, M. Le langage cinématographique. Paris: CERF, 1955, p. 186. [ed. bras MARTIN, M. A linguagem

cinematográfica. Belo Horizonte: Itatiaia, 1963; reed.: A linguagem cinematográfica. 2. ed. São Paulo: Brasiliense, $2009\left(1^{\text {a }}\right.$ ed. 1983); ed. port.: A linguagem cinematográfica. Trad. Vasco Granja e Lauro António. Lisboa: Prelo, 1971; reed.: A linguagem cinematográfica. Trad. Lauro António e Maria Eduarda Colares. Lisboa: Dinalivro, 2005.]

21. KRESS, E. Trucs et illusions: applications de l'optique et de la mécanique au cinématographe. Paris: Comptoir d'édition de "Cinéma-Revue", 1912. p. 3.

22. Em 1908, a Pathé ou Pathé Frères companhia cinematográfica $\mathrm{e}$ fonográfica francesa fundada em 1896, inovou ao inserir filmes comerciais ou documentários antes da exibição dos filmes de longa-metragem. [N.T.]

23. GUIART, J. La vie révélée par le cinématographe. Revue Scientifique, 13 de junho de 1914 vol. I, p. 745.

Durante muito tempo, aliás, as representações cinematográficas não nos mostraram muito mais do que uma roseira que, em alguns segundos, perdia as folhas, as flores e murchava; uma paisagem que se cobria de neve, despojava-se, enchia-se de pastagens e de plantações. ${ }^{19}$

Em 1912, Duran mostra-nos em seu filme Onésime Horloger como o personagem principal, a fim de obter mais rapidamente a posse de uma herança, quebra o relógio do Observatório, após o que os eventos ganham uma aceleração formidável. Uma criança nasce e torna-se adulta em alguns instantes. ${ }^{20}$ Através do cinema, uma ilusão subjetiva da velocidade do tempo pode tornar-se objetiva, realizada sobre a tela. Há também quem explique o sucesso do cinema a partir das possibilidades que ele possui de dar uma forma concreta ao sonho. ${ }^{21} \mathrm{O}$ professor Guiart, durante um filme Pathé ${ }^{22}$ intitulado Eclosion de fleur, que acompanha sua conferência científica, compara-se, em 1914, com "esses faquires indianos que colocam na palma de suas mãos alguns grãos, um pouco de terra e fazem brotar plantas que se recobrem de folhas e de flores, sob os olhos dos maravilhados espectadores". ${ }^{23}$

Graças à "montagem”, à "organização dos planos, em certas condições de ordem e de tempo", ${ }^{24}$ o cinema e a câmera cinematográfica conquistaram um poder ditatorial sobre o tempo e o espaço, criando um tempo e um espaço cinematográfico que diferem do tempo e do espaço matemáticos. O cinema é sempre do tempo presente e o espectador encontra-se sempre no centro dos acontecimentos do filme, seguindo alternadamente os heróis e os bandidos, que podem se encontrar a milhares de quilômetros um do outro. Considerando as decupagens e o "crossing-up", ${ }^{25}$ técnicas não muito utilizadas antes da guerra, os espectadores são levados a trocar de ponto de vista a todo o momento, e observamos que os filmes da época, os filmes de aventura à maneira de Porter, acabam, geralmente, de forma súbita, fazendo com que os espectadores prendam a respiração, enquanto as decupagens e os cortes cada vez mais frequentes precipitam os acontecimentos. Surpreendente seria se essas mudanças rápidas de ponto de vista não tivessem exercido influência sobre muitos autores contemporâneos. A sobreposição, as mudanças rápidas (a "decupagem poética"), a "aceleração", o acúmulo de imagens, a montagem associativa e ilógica e outros procedimentos também encontrados em muitos poetas da época não são, em parte, devidos ao cinema, ainda que tal hipótese pareça um tanto difícil de ser comprovada? Estamos inclinados a crer que diversos poetas, sobre muitos pontos, modelaram seus próprios procedimentos sobre os procedimentos técnicos do cinema, ilustrando, em grande medida, a simultaneidade da vida sobre toda a superfície da terra e, mais ainda, as possibilidades de alcançar uma simultaneidade ilógica e irreal.
25. "Crossing up": quando dois fragmentos de uma mesma história ocorrem simultaneamente em lugares diferentes, a câmera oscila de um a outro. MAGNY, C.-E. L'âge du roman américain. Paris: Editions du Seuil, 1948.

24. MARTIN, op. cit., p. 125 
"O progresso da mecânica, do cinema ensina a ver rápido, a pensar direito 'em velocidade', a discernir com rapidez”, escreveram Bessy e Lo Duca. ${ }^{26}$ Considerando as trucagens relativas ao tempo bem como o movimento característico do cinema, o teatro parece demasiado "estático" aos olhos de muitos jovens no início do século. O teatro obriga-os a esperar vinte minutos entre dois atos que podem acontecer, além do mais, em um mesmo cenário, ao passo que o cinem os leva rapidamente do Pólo Norte ao Saara, de Paris à Índia, com ângulos de visão que mudam sem parar. "O cinema, o que você quer! é o futuro (...). Ele é o companheiro do automóvel, do avião, da T.S.F., das descobertas mecânicas, do conforto, da higiene e da velocidade, rei do tempo! Negar a sua força, o seu poder, a sua ação, é negar o evidente, é negar o século". ${ }^{27}$

Temos tomado por ponto de partida a "máquina" e a "velocidade", os dois elementos fundamentais do "mito do moderno", a fim de delinear as origens do homem "novo", o homem moderno que vive intensamente, que multiplica suas sensações e que, a um grau até então desconhecido, possui um sentido mundial, uma vez que é capaz de ter conhecimento dos eventos contemporâneos que se passam sobre toda a superfície do globo terrestre, até mesmo de experimentar o que acontece quase simultaneamente em lugares muito distantes uns dos outros. Percebemos que mesmo na vida real diária um grande número de coisas ocorre de uma só vez. Por que o mesmo não aconteceria simultaneamente na poesia e nas artes em geral? ${ }^{28}$ Segundo o crítico Octave Béliard, o grande poeta seria, em breve, justamente "aquele que fará fervilhar ao redor de seus estados de espírito todos os movimentos ambientes, simultaneamente", os ruídos do avião e do trem assim como o tique-taque do relógio. ${ }^{29}$ A rapidez tem aberto os olhos de muitas pessoas, "porque a velocidade tem verdadeiramente mudado a face da Terra. Ela renovou toda a nossa estética, todo o nosso prazer de viver" ${ }^{30}$ A velocidade tem ensinado aos "homens novos" a pensar rapidamente, de uma maneira sumária e sintética, e tem-lhes dado novas perspectivas, ${ }^{31}$ frequentemente expressas em uma arte também sintética. Roger Allard escreveu, em tom de brincadeira, em Ecrits français: "O fato de poder transportar-se com uma velocidade extrema de um lugar a outro, parece a muitos de nossos contemporâneos como a mais bela conquista, e a última palavra da Ciência e do Progresso (com maiúsculas)" . ${ }^{32}$ "O homem moderno" ${ }^{33}$ pensa! Ele se encontra sempre no centro dos acontecimentos registrados diretamente, à semelhança de um aparelho Morse, em toda a vida ambiente, explosiva e rodopiante em sua modernidade. Ele prefere o aeródromo e o cinema à igreja, ele tem gosto pelos vôos e pelas viagens de automóvel mais do que pelos museus, ele canta o deus dos tempos novos - o Homem - celebrando o herói do século: o aviador destemido.
28. Ver, por exemplo, Poème \& Drame, vol. VII, janeiro-março de 1914, p. 35 (Aldington)

29. Les hommes du jour, 6 de setembro de 1913 (Les livres).

30. STROWSKI, F. L'homme moderne. Paris: Bernard Grasset, 1931. p. 52.

31. Ver, por exemplo, Pan, fevereiro de 1911, p. 99 ss.

32. ALLARD, R. Futurisme, simultanéisme et autres métachories. Écrits français, 5 de fevereiro de 1914, p. 255.

33. Ver a obra de Strowsky citada acima.

\begin{tabular}{|c|c|c|c|c|c|c|}
\hline EM TESE & BELO HORIZONTE & v. 21 & N. 2 & MAIO-AGO. 2015 & BERGMAN; MACHINSKI. 0 nascimento do cinema e a simultaneidade & p. 152-157 \\
\hline
\end{tabular}


34. Poème \& Drame, janeiro de 1913 vol. II, p. 40-41.
É interessante notar a que ponto extremo esse homem novo procura exprimir seus ideais na literatura já no decorrer dos anos que precedem imediatamente a Grande Guerra. Determinar cronologicamente o nascimento literário de seus ideais é quase impossível. Henri-Martin Barzun, um dos porta-vozes mais entusiastas da "nova beleza", refletiu sobre essa questão. Ele encontra a seguinte solução:

E se obras diversas apresentam-nos (...) um fundo de tendências idênticas, é porque a percepção da nova beleza é simultânea aos nossos olhos; é porque as mesmas formidáveis realidades atacam nossos sentidos; é porque o tempo único em que todos vivemos marca com sua impressão indelével nossas meditações e proporciona à nossa voz o canto moderno. ${ }^{34}$

Barzun nota, também, que essa explicação, aos olhos dos pesquisadores futuros, pareceria bastante simples. Contudo, é a única explicação possível.

No entanto, a julgar pelos críticos, ao que tudo indica, o francês médio ficou chocado ao ler, na primeira página do Le Figaro de 20 de fevereiro de 1909, um manifesto violento e agressivo que pregava, entre outras coisas, uma nova beleza, ou seja, aquela da Velocidade (um automóvel de corrida é mais belo que a Vitória de Samotrácia!), que celebrava o homem ao volante, as cidades modernas, as usinas, as locomotivas e os aviões, manifesto que declarava que o Tempo e o Espaço estariam mortos graças à Velocidade onipresente. A redação do Le Figaro notou, em margem, que o autor do manifesto em questão anunciava a todos "a Escola do Futurismo, na qual as teorias superam em ousadia todas aquelas das escolas anteriores ou contemporâneas". ${ }^{35} \mathrm{O}$ manifesto é assinado "F. T. Marinetti". Algumas palavras preliminares sobre os antecedentes desse homem, notável em muitos aspectos, parecem-nos bastante apropriadas como introdução à primeira parte deste livro.

(A edição referência para esta tradução é: BERGMAN, Pär. "Modernolatria" et "Simultaneità": recherches sur deux tendences dans l'avant-garde littéraire en Italie et en France à la veille de la première guerre mondial. Uppsala: Svenska Bökforlaget/Bonniers, 1962, p. 26-33).
35. Le Figaro, 20 de fevereiro de 1909
EM TESE
BELO HORIZONTE
v. 21
N. 2
MAIO-AGO. 2015
BERGMAN; MACHINSKI. 0 nascimento do cinema e a simultaneidade P. $152-157$

Tradução e Ediç̧ão 